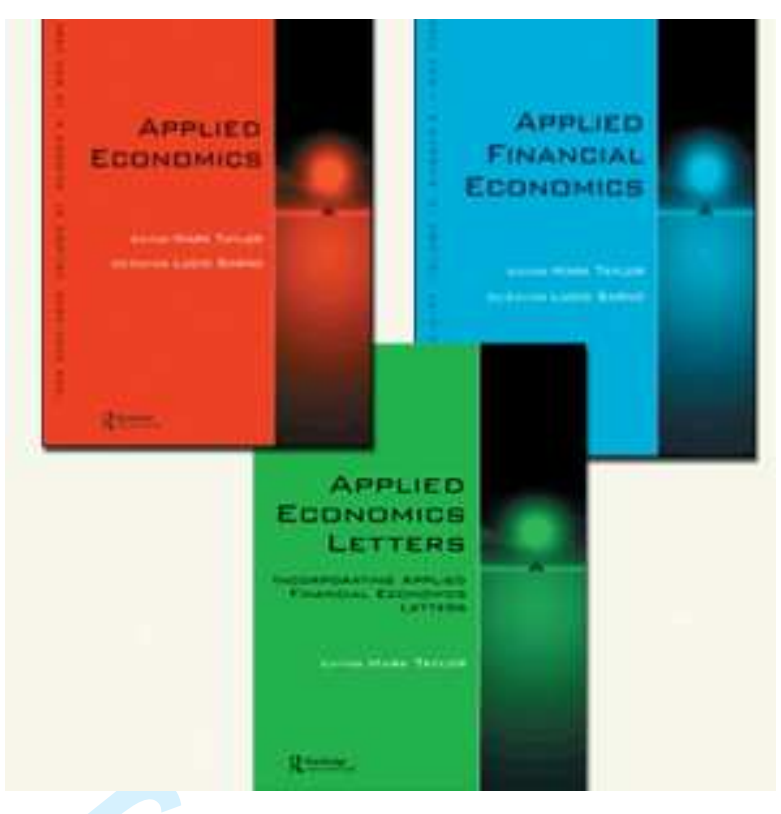

\title{
Time-series properties of the dividend-price ratio with social dynamics
}

\begin{tabular}{|r|l|}
\hline Journal: & Applied Economics \\
\hline Manuscript ID: & APE-2010-0452.R1 \\
\hline Journal Selection: & Applied Economics \\
\hline Date Submitted by the & O6-Apr-2011 \\
\hline Complete List of Authors: & Lawrenz, Jochen; Innsbruck University, Banking and Finance \\
\hline JEL Code: & $\begin{array}{l}\text { G12 - Asset Pricing < G1 - General Financial Markets < G - } \\
\text { Prices, Business Fluctuations, and Cycles < E - Macroeconomics and } \\
\text { Monetary Economics, D80 - General < D8 - Information and } \\
\text { Uncertainty < D - Microeconomics }\end{array}$ \\
\hline Keywords: & $\begin{array}{l}\text { Return predictability, Cointegration, Local interaction, Agent-based } \\
\text { models }\end{array}$ \\
\hline &
\end{tabular}

\section{SCHOLARONE \\ Manuscripts}




\title{
Time-series properties of the dividend-price ratio with social dynamics
}

\author{
Jochen Lawrenz ${ }^{\S}$
}

April 2011

\begin{abstract}
We model an exchange economy where a finite number of standard identical agents interact locally and analyze the time-series properties of the simulated dividend-price ratio $d p_{t}$. Our results document that a sufficient degree of social dynamics induces high persistence in $d p_{t}$ which leads to the failure to reject the null of a unit root, as well as the failure to reject the null that dividends and prices are not cointegrated. At the same time, we find that returns are not significantly autocorrelated, thus, being consistent with weak-form market efficiency. Finally, we document that although $d p_{t}$ is highly persistent, econometric tests may still find predictability of future returns by current dividend-price ratios.
\end{abstract}

JEL classification: G17, G12, D80, E37

Keywords: Return predictability, Predictive regressions, Social dynamics, Hidden Markov Chain, Agent-based models

\footnotetext{
$\S$ Jochen Lawrenz, Department of Banking \& Finance, Innsbruck University, A-6020 Innsbruck, Austria, jochen.lawrenz@uibk.ac.at, Phone +43-512-507-7582.
} 


\title{
Time-series properties of the dividend-price ratio with social dynamics
}

\begin{abstract}
April 2011
Abstract

We model an exchange economy where a finite number of standard identical agents interact locally and analyze the time-series properties of the simulated dividend-price ratio $d p_{t}$. Our results document that a sufficient degree of social dynamics induces high persistence in $d p_{t}$ which leads to the failure to reject the null of a unit root, as well as the failure to reject the null that dividends and prices are not cointegrated. At the same time, we find that returns are not significantly autocorrelated, thus, being consistent with weak-form market efficiency. Finally, we document that although $d p_{t}$ is highly persistent, econometric tests may still find predictability of future returns by current dividend-price ratios.
\end{abstract}

JEL classification: G17, G12, D80, E37

Keywords: Return predictability, Predictive regressions, Social dynamics, Hidden Markov Chain, Agent-based models 


\section{Introduction}

A number of recent empirical studies document the importance of social dynamics between heterogenous agents for the financial asset pricing literature. Yet, only few contributions have sofar tried to analyze the implications of social dynamics for time-series properties of equilibrium asset prices. This paper shows that social dynamics in the sense of the disposition of otherwise identical agents to interact locally induces a significant low-frequency component in financial valuation ratios, like the dividend-price ratio. We document econometric evidence from a simulated economy that the local interaction of agents can account for the high persistence of the dividend-price ratio as well as for the lack of a cointegrating relationship between dividends and prices. Furthermore, we show that the near unit root in valuation ratios complements the findings of return predictability and the absence of significant autocorrelation in returns.

Predictability of stock returns by lagged financial ratios is a long-standing and still controversial research topic among financial economists. Since the early empirical studies that use predictive variables to forecast stock returns as e.g. Rozeff (1984), Fama and French (1988), or Campbell and Shiller (1989), the dividendprice ratio has played a prominent role. Although still subject to ongoing debate, the consensus (as summarized in e.g. Koijen and Van Nieuwerburgh (2009) and Lettau and Ludvigson (2010)) is, that although robust econometric inference is challenging, the dividend-price ratio does indeed have some predictive power. The workhorse of the predictability literature, which is due to Campbell and Shiller (1989), is derived from a present value relation, which states that the log dividend-price ratio can (approximately) be written as

$$
d p_{t}=\mathbb{E}_{t} \sum_{s=1}^{\infty} \rho^{s-1}\left(r_{t+s}-\Delta d_{t+s}\right)+\text { const }
$$

where the $\log$ dividend-price ratio is defined as $d p_{t}=\ln \left(D_{t} / P_{t}\right)$, and $\rho=\frac{e^{\overline{d p}}}{1+e^{d p}}$ and the constant is related to the long-run average log dividend-price ratio $\overline{d p}$. $\Delta d_{t}$ and $r_{t}$ denote the log dividend growth and the log (gross) return respectively. Equation (1), which is sometimes referred to as Campbell and Shiller equation, states that the dividend-price ratio will change if agents anticipate a change in dividend growth, a change in discount rates or both. More importantly, it also shows that if expected dividend growth and expected returns are stationary, then the $\log$ dividend-price ratio needs to be stationary too, and deviations from the 
long-term mean predict future returns, dividend growth or a combination thereof. However, while stationarity of dividend growth and returns can be strongly supported by economic arguments ${ }^{1}$ as well as empirical evidence, tests for stationarity in the dividend-price ratio have failed to reject the null of a unit root (see Campbell and Shiller (1987), or Lettau and Ludvigson (2010) for a recent review). Likewise, if $d p_{t}$ in (1) is assumed stationary, then log dividends and log prices need to be cointegrated with a cointegrating vector $(1,-1)$. Again, the null of no (linear) cointegrating equation is hard to reject, as e.g. Campbell and Shiller (1987), Timmermann (1995), and Han (1996) couldn't find significant evidence for cointegration. ${ }^{2}$

While it remains a challenging task to reconcile the high persistence in the dividend-price ratio and the lack of cointegration between prices and dividends with the evidence for predictability and the implications of rational asset pricing models, Alvarez and Jermann (2005) have shown that a pronounced persistent component in the stochastic discount factor ${ }^{3}$ is necessary to account for the high equity premium, and thus may resolve the alleged equity premium 'puzzle'. Alvarez and Jermann (2005) decompose the stochastic discount factor in a permanent and a transitory component and find in econometric tests the permanent component indeed to be large.

If the stationarity assumption for dividend growth and returns is maintained, then it turns out to be difficult to account for high persistence within a rational representative agent framework. In general, the existing attempts to account for high persistence can be classified into two categories: Either the single representative agent is made more complex in the sense that she exhibits more sophisticated preferences, or models stick with a standard rational agent but augment her endowment process, f.ex. by assuming access to a separate labor income process that may itself exhibit persistence. Prominent attempts in the first category include the consideration of habit formation as in Campbell and Cochrane (1999), Chan and Kogan (2002), or Collard et al. (2006). Models from the second category include Constantinides and Duffie (1996), Lettau and Ludvigson (2001), or Bansal and Yaron (2004).

The purpose of this paper is to show that a third category exists, that has not

1 Non-stationarity would imply counterfactual explosive dividend and price levels.

2 See e.g. Favero et al. (2010) or Esteve and Prats (2010) for more recent evidence.

${ }^{3}$ Persistence in valuation ratios can be traced back to the persistence in the stochastic discount factor. 
yet received sufficient attention: Persistence in the dividend-price ratio, lack of cointegration and the evidence of predictability can be the result of local interaction, or social dynamics of heterogenous agents. We present results from a simulation-based model that the disposition of agents to be influenced by the beliefs of their neighboring agents can account for a pronounced low-frequency component in the aggregate valuation ratio. In particular, we show that a sufficient degree of social interaction can simultaneously account for the facts, that econometric tests cannot reject non-stationarity of prices and dividends, but that the dividend-price ratio displays high persistence, thus leaving open the possibility of a unit root, and that returns are weakly, but not significantly negatively autocorrelated. Furthermore, the null of no cointegrating equation for log dividends and prices cannot be rejected.

Despite the seminal contribution by Shiller (1984), it is only more recently that the implications of social dynamics have gained more attention in the asset pricing literature. In particular, the recent contributions of Hong et al. (2004), Baker and Wurgler (2007), Brown et al. (2008), Grinblatt et al. (2008), or Kaustia and Knüpfer (2010) have shown empirically that social dynamics matter for stock market participation, investment style and more general consumption decisions. This paper adds to this literature by showing within a simulated economy that social dynamics may also explain the observed persistence in valuation ratios and thus relates to the predictability of stock returns.

\section{Theoretical background}

A central theorem in asset pricing states that in arbitrage-free markets there exists a stochastic discount factor $M_{t+1}$ such that the following equation holds,

$$
1=\mathbb{E}_{t}\left(M_{t+1} R_{t+1}\right)
$$

where $R_{t+1}$ denotes the gross return on a traded asset. ${ }^{4}$ Using the definition of gross return on a dividend-paying stock as $R_{t+1}=\frac{P_{t+1}+D_{t+1}}{P_{t}}$ and straightforward manipulations of (2), we obtain,

$$
P D_{t}=\mathbb{E}_{t}\left(M_{t+1}\left(P D_{t+1}+1\right) D_{t+1} / D_{t}\right)
$$

\footnotetext{
${ }^{4}$ See e.g. Cochrane (2001).
} 
for the price-dividend ratio $P D_{t}$. Within the most basic equilibrium asset pricing model, where a single representative agent with standard preferences consumes aggregate consumption, the stochastic discount factor is determined by this agent's first-order conditions. With power utility, it turns out to be $\delta\left(D_{t+1} / D_{t}\right)^{-\gamma}$, where $\delta$ is the subjective time discount factor and $\gamma$ denotes the risk aversion parameter. By further assuming constant dividend growth, it is straightforward to show that the price-dividend ratio is constant and equals

$$
P D_{t}=\frac{d}{(1-d)}, \quad \text { where: } \quad d=\delta \exp \left\{1 / 2(1-\gamma)\left(2 \mu-\gamma \sigma^{2}\right)\right\},
$$

and $\mu, \sigma^{2}$ are the growth rate and variance of the dividend process.

Empirically, $P D_{t}$ is not only not constant, but displays high persistence. How can the counterfactual constant price-dividend ratio be reconciled with the empirical evidence of time-variation and more importantly with the high persistence? A simple way would be to assume a time-varying dividend growth as e.g. in Bansal and Yaron (2004) or Collard et al. (2006), who assume an AR(1) process for the dividend growth rate. However, this approach does not yield an economic explanation how significant persistence arises in the first place. One approach, that tries to provide economic intuition for the emergence of persistence, is to maintain the assumption of a representative agent, but to augment her preferences. Habit persistence models as e.g. Campbell and Cochrane (1999) assume that utility is defined over the difference between consumption and a habit level, which they capture through a surplus consumption ratio $S_{t}{ }^{5}$ By sticking to the assumption of power utility, they show that the stochastic discount factor $M_{t+1}$ turns out to be $M_{t+1}=\delta\left(\frac{S_{t+1}}{S_{t}} \frac{D_{t+1}}{D_{t}}\right)^{-\gamma}$, and thus varies with the growth in the surplus consumption ratio. However, the evolution of the habit level is still exogenous to the model, and Campbell and Cochrane (1999) assume that the log surplus ratio $s_{t}$ follows an AR(1) model. Thus, although Campbell and Cochrane (1999) can successfully accommodate a number of stylized facts, the persistence in the pricedividend-ratio, as seen from (3), can still be traced back to an exogenous AR(1) assumption. A second, distinct approach is to allow for heterogeneity of agents. A prominent contribution is due to Constantinides and Duffie (1996), who consider identical agents with standard preferences, but with different consumption levels, due to heterogeneity in individual income processes. They show that the stochastic discount factor in (3) assumes the form $M_{t+1}=\delta\left(\frac{C_{t+1}}{C_{t}} \exp \left\{\frac{\gamma(\gamma+1)}{2} y_{t+1}^{2}\right\}\right)$,

${ }^{5}$ For the definition and discussion, see Campbell and Cochrane (1999), p. 209. 
where $C_{t}$ denotes aggregate consumption. The term $y_{t+1}^{2}$ is the variance of the cross-sectional distribution of $\log \left(\tilde{c}_{i, t+1} / \tilde{c}_{i, t}\right)$, where $\tilde{c}_{i, t}$ is the fraction of agent $i$ 's consumption to aggregate consumption. The variance term $y_{t+1}^{2}$ is thus influenced by the assumption that idiosyncratic income shocks are assumed to follow random walks, and thus that the income processes, which in turn influence the fractional consumption, are nonstationary. However, from (3), persistence in $P D_{t}$ can be traced back to an exogenously given nonstationary (labor income) process. A recent contribution by Favero et al. (2010) argues that the low-frequency component may be explained by slowly changing demographic trends. Within an overlapping generations model, they introduce a demographic variable $M Y$, which they define as the ratio of middle-aged to young people, and show that $M Y$ is able to explain a significant part of the slowly evolving mean of the dividend-price ratio.

Our simulation model offers a third approach how to account for persistence and more importantly, how persistence can arise endogenously without having to recur to the assumption of an exogenous nonstationary process.

\section{Model description}

Our economy is populated by a finite number $N$ of agents with identical standard preferences, described by power utility over consumption, i.e. $u\left(c_{t}\right)=c_{t}^{1-\gamma} /(1-\gamma)$. In line with the bulk of the literature, we consider a pure exchange economy in the tradition of Lucas (1978), where an exogenous stochastic non-storable endowment process exists, which is traded in the form of one unit of dividend-paying stock. Dividend dynamics are assumed to follow the discretized version of a standard diffusion process, i.e.

$$
D_{t}=D_{t-1} \exp \left\{\left(\mu_{t}-\sigma_{D}^{2} / 2\right)+\sigma \epsilon_{t}\right\},
$$

where the $\epsilon_{t}$ are standard normal iid, and $\sigma$ is constant. We follow e.g. Cecchetti et al. (2000) and allow for time-variation in the drift term by assuming that $\mu_{t}$ can take on two possible values $\mu_{t} \in\left\{\mu_{h}, \mu_{l}\right\}$ with $\mu_{h} \geq \mu_{l}$, and assume that there exists a $2 \times 2$ transition matrix T. ${ }^{6}$ Agents cannot observe the state of the actual

${ }^{6}$ Thus, the dividend process can be characterized as a Markov switching process (Hidden Markov Chain) with an underlying binomial state variable. Such a specification has been advanced by Hamilton (1989) to characterize the business cycle. 
growth rate. However, since the growth of dividends is crucial to their consumption decision, they need to form beliefs. We assume that every agent's belief is influence by three factors: (i) Every agent has some individual belief about the state of the economy which is assumed to be purely idiosyncratic. (ii) As fundamental information, every agent has access to a current estimate of the growth rate from observing the past dividend process in the sense of Bayesian updating. This global piece of information can be considered as a publicly available economic outlook report. The estimate $\hat{\mu}(t)$ expresses the probability that the economy grows at the high rate $\mu_{h}$, i.e. $\hat{\mu}_{t}=\operatorname{Prob}\left\{\mu_{t}=\mu_{h} \mid\left(D_{\tau}\right)_{\tau \leq t}\right\}$. (iii) Most importantly for our purposes, every agent is assumed to pay attention to the beliefs of her neighboring agents, thereby inducing local interaction, i.e. social dynamics. To formalize the last point, we need to impose some topology on our economy. We assume that the $N$ agents can be ordered on a stable ring-network, where we define the neighborhood of agent $i$ as $\mathbb{N}_{i}=\{j ;(i-1) \bmod N \leq j \leq(i+1) \bmod N\}$, i.e. $\mathbb{N}_{i}$ is the set of the nearest adjacent agents on the ring. ${ }^{7}$ As each agent knows that the growth rate of the economy can either be high or low, we consider agents to assume two states $S_{i}(t)=s$ with $s \in\{0,1\}$, corresponding to the agent being either optimistic or pessimistic. With analogous notation, $S_{\mathbb{N}_{i}}(t)$ denotes the collective state of agent $i$ 's neighborhood at time $t .^{8}$ For the temporal evolution, each agent's state is updated every time step according to

$$
S_{i}(t)=f\left(S_{\mathbb{N}_{i}}(t-1), \hat{\mu}(t), \theta\right)
$$

where $\theta$ is a vector of two controlling parameters $\theta=\left(\theta_{g}, \theta_{\mathbb{N}}\right)$ (normalized to $0 \leq \theta_{g}, \theta_{\mathbb{N}} \leq 1$ ) that govern the extent to which the agent's belief is influenced by the three factors. More precisely, we assume that $f$ assumes the form,

$$
S_{i}(t)=\left\{\begin{array}{ll}
0 & \text { with probability }\left(1-\pi_{i, t}\right) \\
1 & \text { with probability } \pi_{i, t}
\end{array},\right.
$$

where the probability $\pi_{i, t}$ is determined by a function $g:[0,1] \rightarrow[0,1]$ which is continuous and monotonically increasing, and whose argument is the weighted average of the state of the neighborhood and the global information defined as $\overline{S_{i}(t)}=\theta_{\mathbb{N}} S_{\mathbb{N}_{i}}(t-1)+\left(1-\theta_{\mathbb{N}}\right) \hat{\mu}(t)$. Thus, $\pi_{i, t}=g\left(\overline{S_{i}(t)} ; \theta_{g}\right)$. The curvature of $g$ is governed by $\theta_{g}$ such that we have the following properties: For $\theta_{g} \rightarrow 0$,

\footnotetext{
7 See e.g. Jackson (2008) for the concepts of networks.

${ }^{8}$ We define the collective state of the neighborhood as the equally weighted average of the states of the agents in the neighborhood, i.e. $S_{\mathbb{N}_{i}}=\left|\mathbb{N}_{i}\right|^{-1} \sum_{k \in \mathbb{N}_{i}} S_{k}$.
} 
$\pi \rightarrow 1_{\left\{\overline{S_{i}(t)}>1 / 2\right\}}$, while for $\theta_{g} \rightarrow 1, \pi \rightarrow 1 / 2$. In economic terms, $\theta_{g}$ determines to what extent, the agent is influenced by the internal, idiosyncratic factor, while $\theta_{\mathbb{N}}$ determines to what extent the agent is influenced by her neighborhood. Thus, if $\theta_{g} \rightarrow 1$, then the internal, idiosyncratic factor dominates, and the agent is not influenced by either the economic outlook or the state of her neighborhood. On the contrary, if $\theta_{g} \rightarrow 0$, then external factors dominate, and it depends on $\theta_{\mathbb{N}}$ if the global information or the local neighborhood is more important. If $\theta_{\mathbb{N}} \rightarrow 0$, the agent relies exclusively on the information of the global economic outlook, while for $\theta_{\mathbb{N}} \rightarrow 1$, the agent relies exclusively on the lagged state of her neighborhood $S_{\mathbb{N}_{i}}(t-1)$.

Conditional on being in state $s=0$, the agent expects the economy to grow at the rate $\mu(0)=\mu_{l}$, and vice versa, which in turn determines her consumption decision via the maximization of her expected life-time utility $U\left(c_{t}\right)=\mathbb{E}\left(\sum_{j=0}^{\infty} \delta^{j} u\left(c_{t+j}\right)\right)$. The consumption decision of each agent induces her demand for the risky asset $x_{t}$, which can be shown to assumes the form

$$
x_{t}^{(s)}=\frac{\tilde{\mathcal{V}}^{(s)} x_{t}^{-}\left(1+\omega_{t}\right)}{\tilde{\mathcal{V}}^{(s)} \omega_{t}+\omega_{t}^{1 / \gamma}},
$$

where $\omega_{t}=P_{t} / D_{t}$ is the price-dividend ratio, $\mathcal{V}^{(s)}=\left(d^{(s)} /\left(1-d^{(s)}\right)\right)^{1 / \gamma}$, and $d^{(s)}$ is defined as in (4) for a state-dependent growth rate $\mu(s)$. Thus, demand depends on the current wealth of the agent $x_{t}^{-}$, the current price-dividend ratio, and the belief of the agent about the state of the economy in a non-linear way. It can further be verified that for $\gamma>1, x_{t}^{(1)}<x_{t}^{(0)}$, i.e. an agent who expects higher growth rates, consumes more today and thus has a smaller demand for the risky asset. $^{9}$

Finally, the market-clearing condition requires that the aggregate demand meets the normalized supply of the asset, which determines its current price. Note further, that we can define an aggregate state of the economy as the average of the individual states, which we denote by $S(t)=N^{-1} \sum_{i} S_{i}(t)$. $S(t)$ can be interpreted as the fraction of optimists in the economy, and is thus a measure of the aggregate opinion, or a sentiment index for the economy.

\footnotetext{
${ }^{9}$ See Hule and Lawrenz (2010) for a more comprehensive discussion of the model.
} 


\section{Results}

Within our model economy, our interest is on the time-series properties of the simulated dividend-price ratio as we vary the controlling vector $\theta$. In particular, this section presents results from (i) stationarity tests, (ii) estimated autoregression coefficients, and (iii) cointegration test. We run our simulation model with $N=300$ agents over $T=500$ time steps. A time step is considered to be one month. The dividend process parameters are calibrated to roughly match historical data (on an annual basis), thus $\mu_{l} \cdot 12=0.0225, \mu_{h} \cdot 12=0.015$, and $\sigma \cdot \sqrt{12}=0.04 .{ }^{10}$ Risk aversion is $\gamma=3$, and the (monthly) time discount factor is $\delta=0.995$. For each simulation run, we evaluate the model on a grid for the controlling vector $\theta$ with interval length 0.05 , i.e. for 400 parameter constellations, by holding fixed the seed of the random number generator. Each simulation run results in a time-series for log dividends, and log prices, from which the log dividend-price ratio and the return series are constructed. Additionally, we report the time-series for the aggregate opinion $S(t)$ in the economy, which is defined as the cross-sectional average over the agents' states $S_{i}(t)$. We conduct econometric tests for each simulated time series, and report average results over $K=100$ simulation runs.

In testing for non-stationarity, we report the results of the Phillips-Perron (PP) unit root test, as well as the results of the Kwiatkowski-Phillips-Schmidt-Shin (KPSS) test, which reverses the null and thus has the stationarity assumption by default. Using PP and KPSS test jointly is known as confirmatory data analysis. With respect to the log dividend and price series we can never reject the null of the PP test, and analogously can always reject the null at the $1 \%$ level for the KPSS test, thus, confirming that log dividend and prices are non-stationary for any of the 400 parameter choices. For returns, we always reject the unit root at $1 \%$ and never reject stationarity for any parameter choice. Thus, we have strong evidence that log dividends and prices can be considered $I(1)$.

Testing for non-stationarity of the log dividend-price ratio, however, delivers different results, which are visualized in figure 1, where we report significance levels for the PP test (left panel), and the KPSS test (right panel). Black squares represent a $p$-value of less than 0.01 for the corresponding parameter choice, dark grey squares for $0.01<p<0.05$, light grey squares for $0.05<p<0.1$, and white squares indicate an insignificant result for the corresponding parameter constella-

\footnotetext{
10 See e.g. Cecchetti et al. (1990), Goyal and Welch (2003), and Mehra and Prescott (2003).
} 
1

2

3

4

5

tion. From the PP test a unit root in the log dividend-price ratio cannot always be

Figure 1: Stationarity tests for the log dividend-price ratio $d p_{t}$.

\begin{abstract}
The left panel shows the $p$-values from a Phillips-Perron $(P P)$ unit root test, while the right panel shows $p$-values from a Kwiatkowski-Phillips-Schmidt-Shin (KPSS) stationarity test performed on the simulated log dividend-price ratio $\left(d p_{t}\right)$ series for parameter values ranging between $0.05 \leq \theta_{\mathbb{N}}, \theta_{g} \leq 1$ in intervals of 0.05 . Black squares correspond to $p$-values below 0.01 , dark grey squares for $0.01<p<0.05$, light grey squares for $0.05<p<0.1$, and white squares for $p$-values above $10 \%$.
\end{abstract}
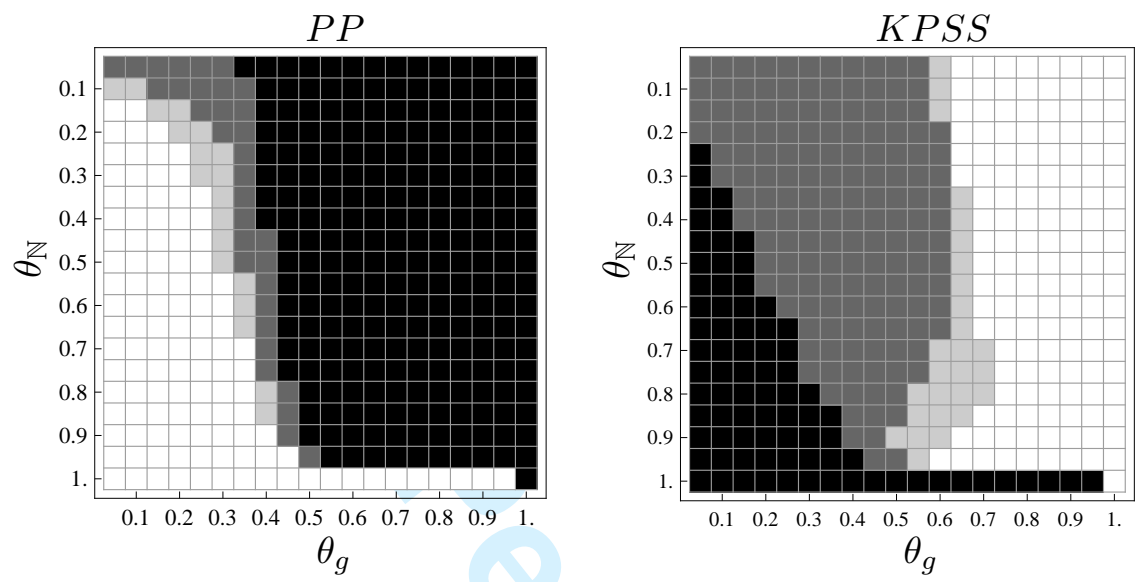

rejected, and likewise from the KPSS test, stationarity can be rejected for a number of parameter constellations. Thus, there exist parameter combinations, where the $d p_{t}$ series displays high persistence. In particular, these are constellations in the lower left part of the panels in figure 1, i.e. for low values of $\theta_{g}$ (horizontal axis) and high values of $\theta_{\mathbb{N}}$ (vertical axis). These are parameter choices where individual agents are only to a small extent influenced by idiosyncratic factors, but pay significant attention to the lagged beliefs of their neighborhood. Thus, the possibility that econometric tests may fail to reject the null of a unit root (and vice versa, succeed in rejecting the null of stationarity) can be due to a high degree of social dynamics in the sense of local interaction. To further strengthen this finding, we report in figure 2 the estimated autoregression coefficient $\hat{\beta}$ from a least square estimation, and significance levels, where standard errors are Newey-West corrected for heteroscedasticity. The upper left panel displays the autoregression coefficient $\hat{\beta}_{d p}$ from the regression: $d p_{t}=\alpha+\beta_{d p} d p_{t-1}+\epsilon_{t}$, while the upper right panel reports $\hat{\psi}$ from the autoregression of returns: $r_{t}=\alpha+\psi r_{t-1}+\epsilon_{t}$. The lower panels report significance levels. We find decreasing values for $\hat{\beta}_{d p}$ as $\theta_{g}$ increases, in line with the findings from the stationarity test. From the lower panel, only 
Figure 2: Autoregression coefficients for the log dividend-price ratio and returns.

The two panels on the left show result from estimating the autoregressive equation $d p_{t}=\alpha+\beta_{d p} d p_{t-1}+\epsilon_{t}$. The upper panel reports the autoregression coefficient $\hat{\beta}_{d p}$ of the $\log$ dividend-price ratio, while the lower panel reports significance levels. The two panels on the right show results from estimating the autoregressive equation $r_{t}=\alpha+\psi r_{t-1}+\epsilon_{t}$. The upper panel reports the autoregression coefficient $\hat{\psi}$ of the return, while the lower panel reports significance levels. Standard errors are Newey-West corrected for heteroscedasticity. In the lower panels, black squares correspond to $p$-values below 0.01 , dark grey squares for $0.01<p<0.05$, light grey squares for $0.05<p<0.1$, and white squares for $p$-values above $10 \%$.
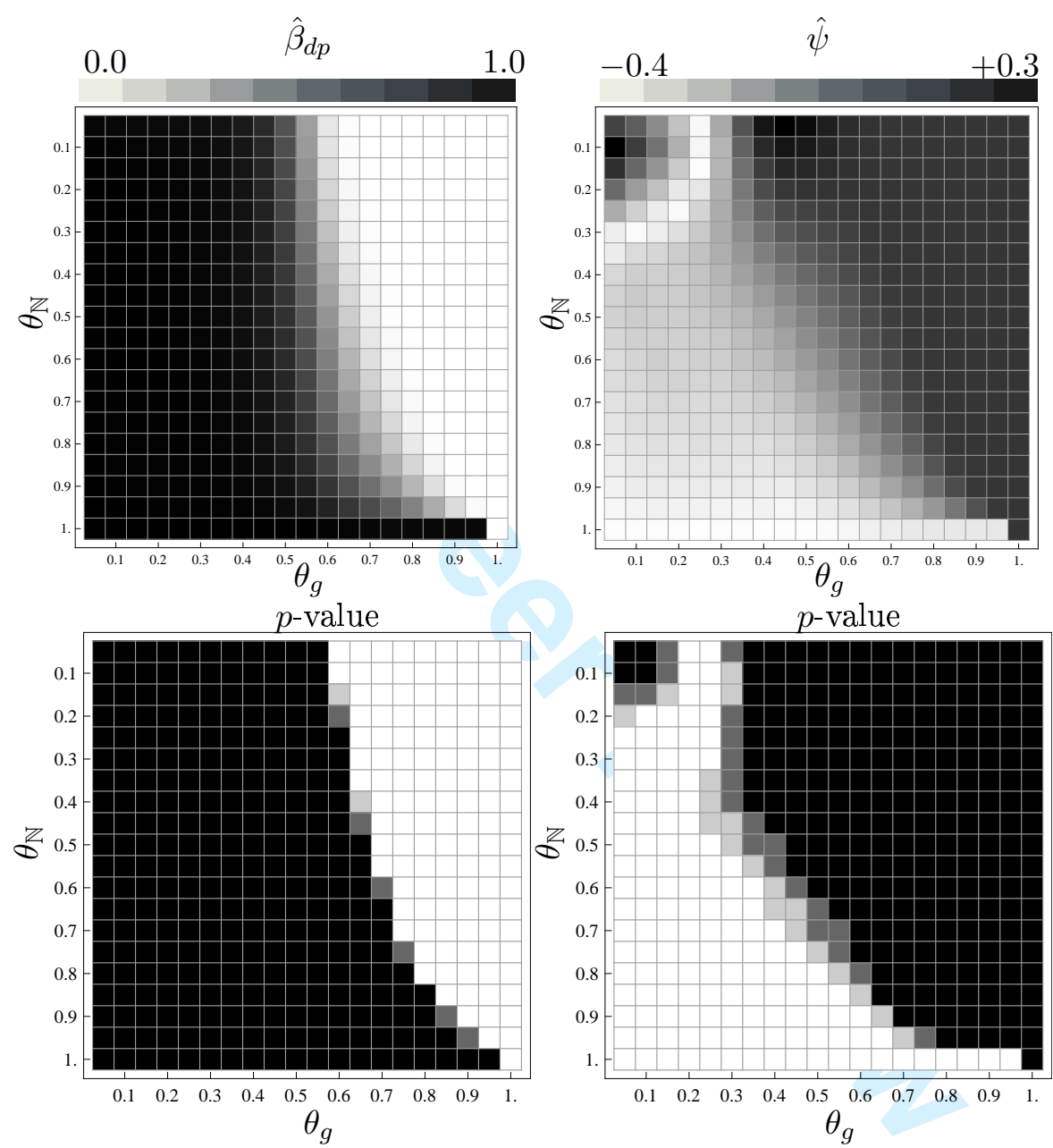

high autoregression coefficients tend to be significant. For low $\theta_{g}$ and high $\theta_{\mathbb{N}}$, we find values for $\hat{\beta}_{d p}$ of around 0.97 , consistent with empirical evidence as e.g. in Cochrane (2008) or Lewellen (2004).

For similar parameter constellations, where $\hat{\beta}_{d p}$ is significantly near unity, the right panels in figure 2 show that the autoregression coefficients $\hat{\psi}$ are negative and around -0.03. Although the negative return autocorrelation would imply 
1

2

3

4

5

6

7

8

9

mean-reverting prices, they are not statistically significant as the lower right panel confirms, where we report $p$-values (from Newey-West adjusted standard errors). Thus, while the dividend-price ratio is highly persistent, the economy is still weak-form efficient, as we find no significant predictability from past returns.

As a third piece of evidence, we report the results of a Johansen cointegration test. ${ }^{11}$ As the previous tests have established that the log dividend and price series can be considered as $I(1)$, we first test for a cointegrating relationship between log dividends and $\log$ prices. Figure 3 reports the significance level for the null that no cointegrating equation exists (left panel), as well as the normalized cointegrating coefficient (right panel). The results confirm that for roughly the

Figure 3: Johansen cointegration test for $\left(d_{t}, p_{t}\right)$

The left panel reports the (MacKinnon-Haug-Michelis (1999)) $p$-values (Trace statistic) for the null of no cointegrating equation in log dividends and prices in the Johansen Cointegration test. Black squares correspond to $p$-values below 0.01 , dark grey squares for $0.01<p<0.05$, light grey squares for $0.05<p<0.1$, and white squares for $p$-values above $10 \%$. The right panel reports the normalized cointegrating coefficient. Black squares correspond to deviations from -1 of less than 0.05 , dark grey squares correspond to deviation between 0.05 and 0.1 , light grey squares correspond to deviations between 0.1 and 0.2 , and white squares correspond to deviation larger than 0.2 .
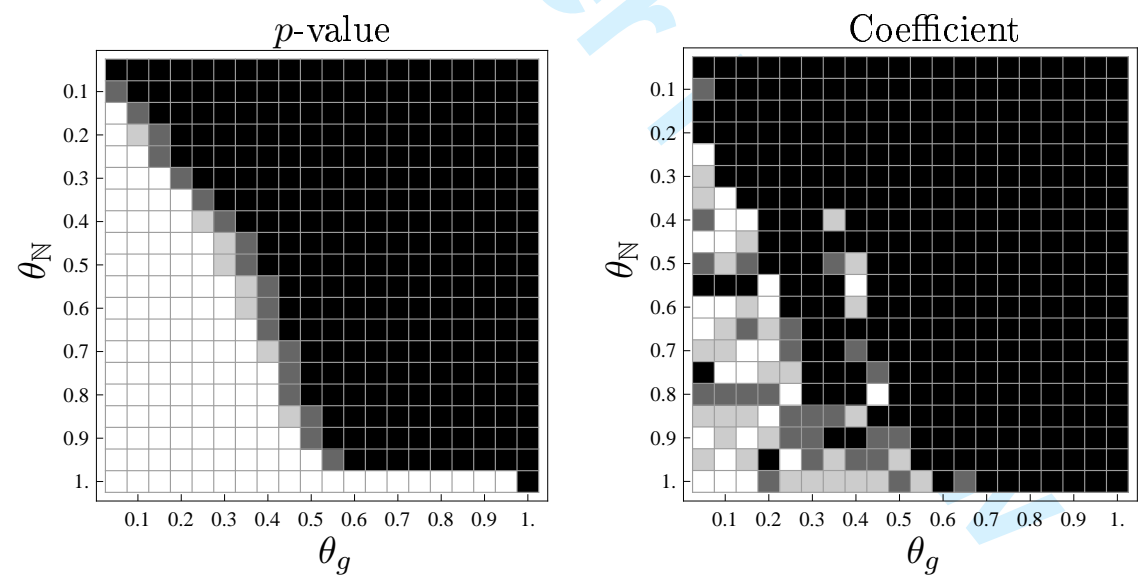

same parameter constellations, where we could not reject the null of a unit root in the $d p_{t}$ series, we also cannot reject the null that no cointegrating equation

11 Cointegration analysis has a long tradition in studying e.g. the purchasing power parity (see e.g. Taylor, 1988; Masih and Masih, 2004; Haug and Basher, 2011), but has also been applied to price and dividend time series as in e.g. Timmermann (1995); Han (1996). 
exists for log dividends and prices. ${ }^{12}$ From the right panel, we find that for those parameter constellations where the trace statistic rejects the null at $1 \%$ or better, the normalized cointegrating coefficient is $-1 \pm 0.05$ (black squares) as theoretical arguments suggest it should be. Only for cases where the null cannot be rejected, the coefficient deviates substantially from -1 (grey and white squares).

The results from the cointegration test show that there exists a cointegrating vector $(1,-1)$ for dividends and prices when agents form beliefs largely independent of each other. If agents interact more strongly, then the cointegrating relationship can no longer be confirmed statistically. However, we may augment the cointegration test to incorporate the measure for the aggregate opinion in the economy, $S(t)$. Before we report results from the Johansen cointegration test on the vector of variables $\left(d_{t}, p_{t}, S(t)\right)$, we investigate stationarity of the aggregate opinion time series in figure 4 . The upper panels report the results of the confirmatory data analysis, i.e. the $p$-values of the PP test (left panel), as well as the KPSS test (right panel). The pattern is almost identical to the one observed from the stationarity results on the dividend-price ratio as shown in figure 1 . For low values of $\theta_{g}$, and high values of $\theta_{\mathbb{N}}$, i.e. a significant disposition of agents to interact locally, we find that the aggregate opinion in the economy displays a high degree of persistence, such that a unit root cannot be rejected (stationarity can strongly be rejected). This is further confirmed by the estimated autoregression coefficient $\hat{\beta}_{S}$ from the regression: $S_{t}=\alpha+\beta_{S} S_{t-1}+\epsilon_{t}$, which is reported in the lower left panel. Corresponding significance levels are in the lower right panel. Consistent with the results from the stationarity test, $\hat{\beta}_{S}$ is significantly close to unity for parameter constellations where agents are strongly influenced in their investment decision by their neighborhood.

As the aggregate opinion time series can be considered $I(1)$ at least for a subset of the parameter constellations, we can conduct a cointegration test on the vector of variables $\left(d_{t}, p_{t}, S(t)\right)$. Results from the corresponding Johansen test are reported in figure 5 . The panels show the $p$-values for the null that no cointegrating vector exists for the Trace statistic (left panel) and the Maximum Eigenvalue statistic (right panel). By comparing the results from the cointegra-

12 The left panel reports the $p$-value for the Johansen Trace statistic. We obtain exactly similar results when plotting the $p$-values for the Maximum-Eigenvalue statistic. 
Figure 4: Stationarity test and autoregression coefficient for $S(t)$.

The upper left panel reports the $p$-values from the Phillips-Perron $(P P)$ unit root test, while the right panel shows $p$-values from a Kwiatkowski-Phillips-Schmidt-Shin $(K P S S)$ stationarity test performed on the aggregate opinion time series $(S(t))$ for parameter values ranging between $0.05 \leq \theta_{\mathbb{N}}, \theta_{g} \leq 1$ in intervals of 0.05 . Black squares correspond to $p$-values below 0.01 , dark grey squares for $0.01<p<0.05$, light grey squares for $0.05<p<0.1$, and white squares for $p$-values above $10 \%$. The lower left panel shows the estimated autoregression coefficient $\hat{\beta}_{S}$ from the regression: $S_{t}=\alpha+\beta_{S} S_{t-1}+\epsilon_{t}$. The lower right panel reports the corresponding significance levels.
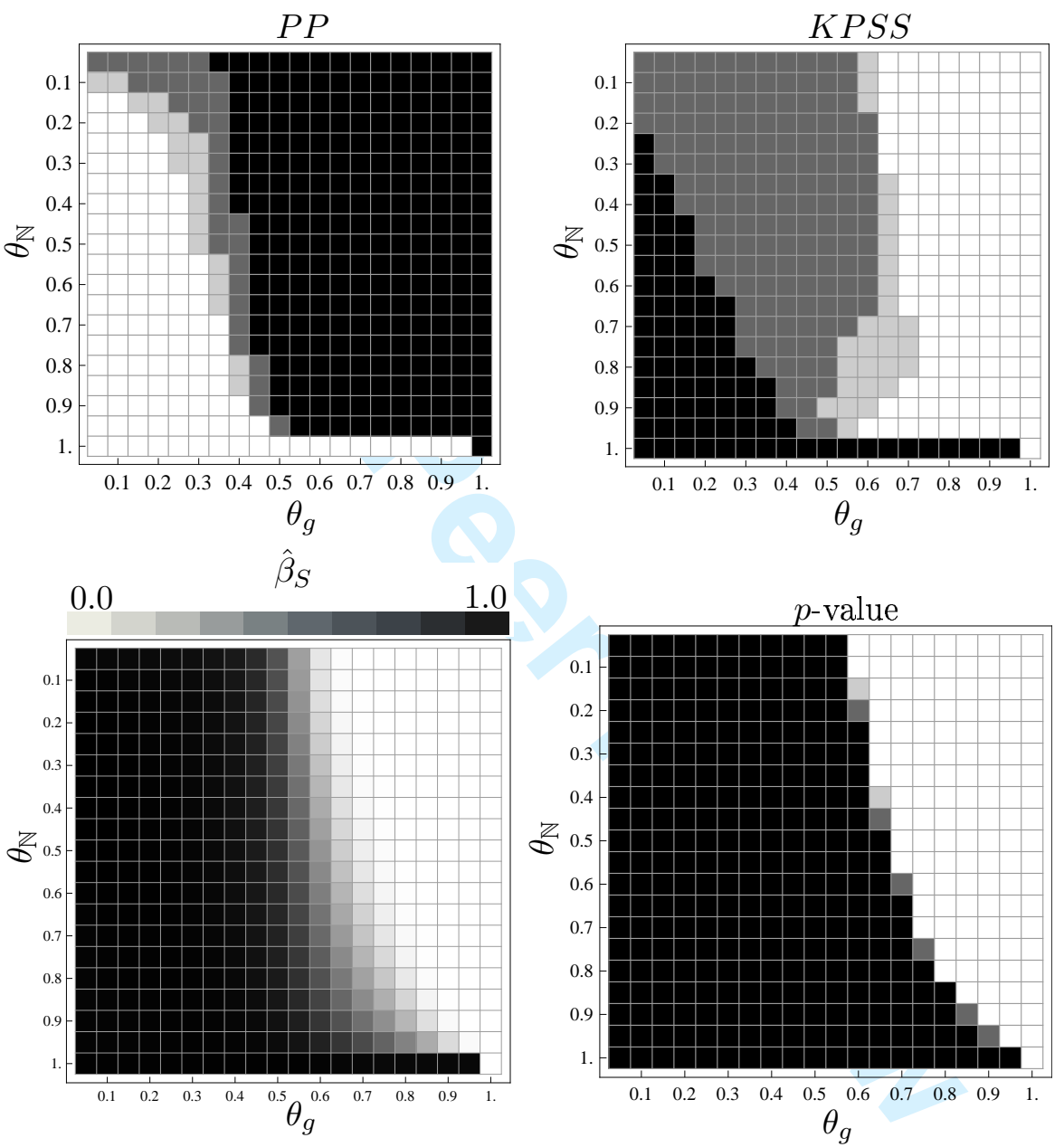

tion test on the vector of variables $\left(d_{t}, p_{t}\right)$ in figure 3 with the results on the vector $\left(d_{t}, p_{t}, S(t)\right)$, which is augmented by the aggregate opinion in figure 5 , we observe that there is weak evidence ( $p$-values between $5 \%$ and $10 \%$ ) that the null of no cointegrating vector can now be rejected for the parameter cases where $\theta_{g}$ is low and $\theta_{\mathbb{N}}$ is high. Thus, there is (weak) evidence that for a high degree of social dynamics prices track the aggregate opinion in the economy. If we consider the 
Figure 5: Johansen cointegration test for $\left(d_{t}, p_{t}, S(t)\right)$.

The panels report (MacKinnon-Haug-Michelis (1999)) $p$-values levels for the Johansen cointegration test on the three-dimensional vector of variables $\left(d_{t}, p_{t}, S(t)\right)$ for the Trace statistic (left panel), and the Maximum Eigenvalue statistic (right panel) for the null of no cointegrating vector. Black squares correspond to $p$-values below 0.01 , dark grey squares for $0.01<p<0.05$, light grey squares for $0.05<p<0.1$, and white squares for $p$-values above $10 \%$.
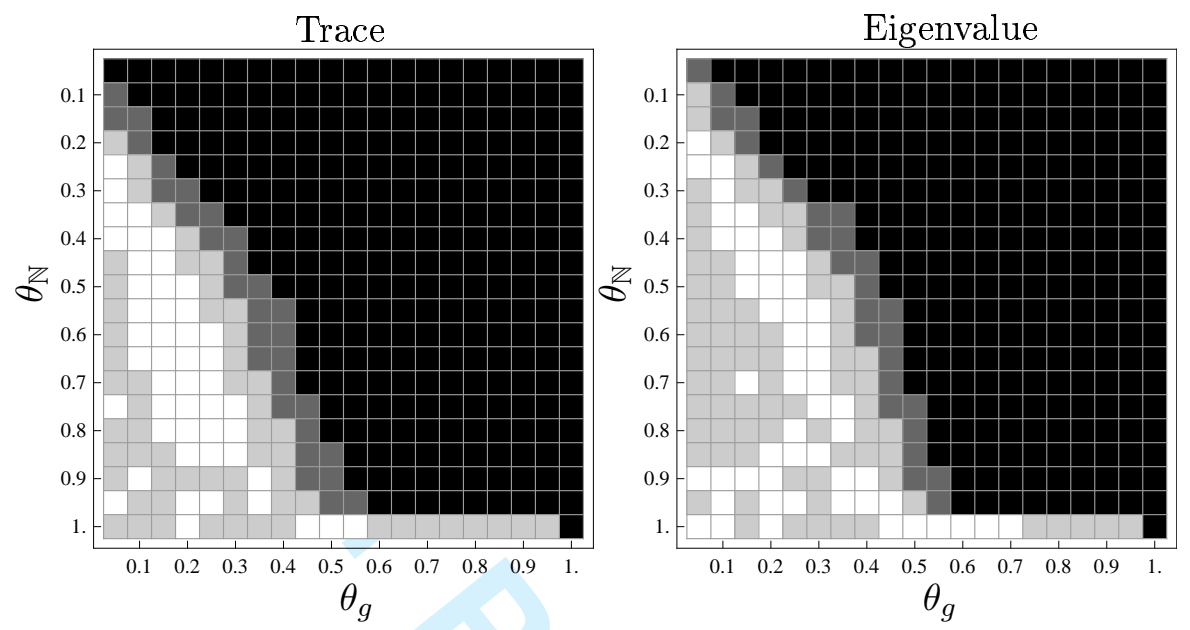

aggregate opinion as a sentiment index in the sense of Baker and Wurgler (2007), we have some evidence that sentiment is actually a priced factor in financial markets.

A substantial literature, going back to work by Rozeff (1984), Fama and French (1988), or Campbell and Shiller (1989) has examined the possibility to predict future returns by current valuation ratios like the dividend-price ratio. ${ }^{13}$ Although not being the focus of this contribution, ${ }^{14}$ we report results form the predictive regression $r_{t}=\alpha+\beta_{r} d p_{t-1}+\epsilon_{t}$ in figure 6 , where the left panel shows the estimated predictive coefficient $\hat{\beta}_{r}$, and the right panel reports the corresponding $p$-values. We find that consistent with equation (1), the dividend-price ratio has strong predictive power when it displays stationarity, which is the case for high values of $\theta_{g}$, i.e. when heterogenous agents act independently. As agents interact more strongly, the dividend-price ratio becomes more persistent, as shown in the previous sections, and correspondingly its predictive power weakens. For low values of $\theta_{g}$ and high values of $\theta_{\mathbb{N}}$, the predictive regression yields insignificant

\footnotetext{
13 See also Masih et al. (2010) for a recent contribution that applies a Bayesian approach and Chen and Zhang (2007), who consider structural breaks in predictive regressions.

14 For a more comprehensive analysis of the evidence of predictability in an exchange economy with social dynamics, see Hule and Lawrenz (2010).
} 
Figure 6: Predictive regression.

The left panel reports the value for the estimated coefficient $\hat{\beta}_{r}$ form the predictive regression $r_{t}=\alpha+\beta_{r} d p_{t-1}+\epsilon_{t}$. The right panel reports corresponding $p$-values. Standard errors are Newey-West corrected for heteroscedasticity. In the right panel, black squares correspond to $p$-values below 0.01 , dark grey squares for $0.01<p<0.05$, light grey squares for $0.05<p<0.1$, and white squares for $p$-values above $10 \%$.
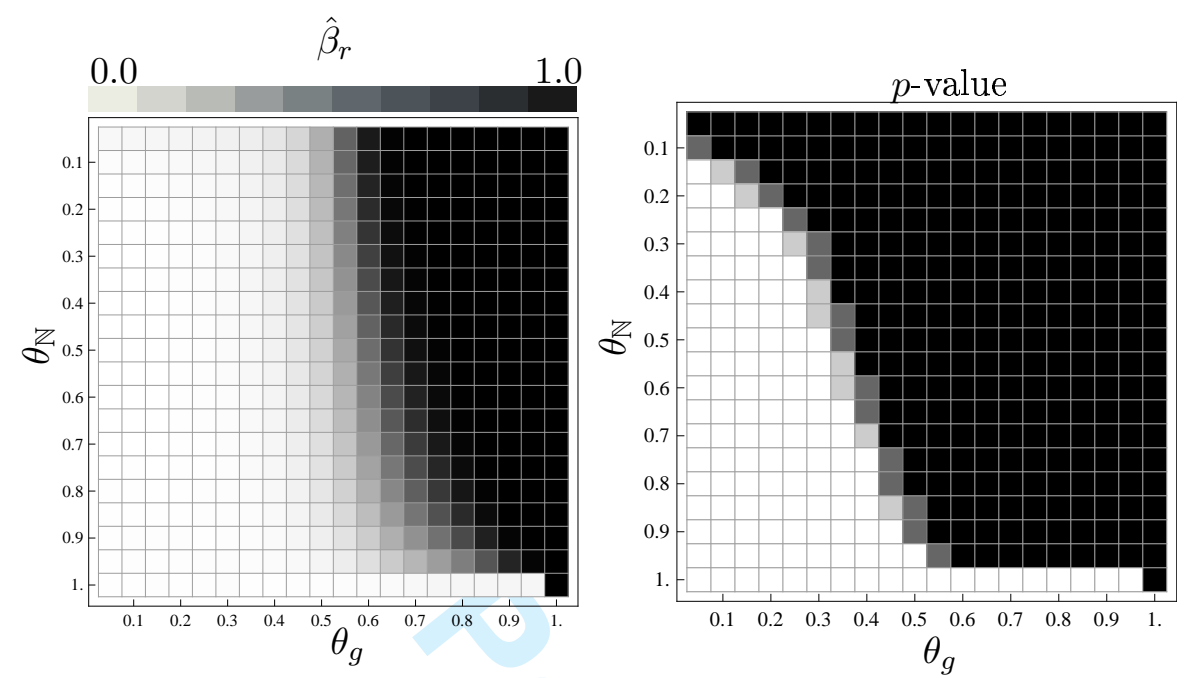

results. However, there exist parameter constellations where we find significant predictive coefficients of around 0.1 which is roughly consistent with empirical evidence as reported in Cochrane (2008), Ang and Liu (2007), or Lettau and Van Nieuwerburgh (2008).

Taken together, the econometric evidence from our simulated economy with interacting agents suggests that there exist parameter constellations, for which we cannot reject the null of a unit root (where we can strongly reject the null of stationarity) in the $\log$ dividend-price ratio as well as in a sentiment measure. The estimated autoregression coefficient in the dividend-price ratio is significantly around 0.97 , while the (negative) autoregression coefficient in returns is insignificant. Furthermore, we cannot reject the null that no cointegrating equation for log dividends and prices exists. At the same time, the predictive regression yields weak evidence that the dividend-price ratio predicts future returns. The parameter constellation which leads to this evidence is one, where heterogenous agents display a significant disposition to be influenced by the lagged beliefs of their neighborhood (i.e. for high values of $\theta_{\mathbb{N}}$ and low values of $\theta_{g}$ ). 


\section{Conclusion}

Recent work stresses the importance to explain the low-frequency component in valuation ratios like the dividend-price ratio. If dividend growth and returns are stationary, as is strongly supported by empirical evidence, then straightforward theoretical arguments suggest that the dividend-price ratio should be stationary too. The stationarity in the valuation ratio should in turn lead to predictability of future returns. However, empirical evidence sofar couldn't reject the null of non-stationarity and provided strong evidence for high persistence. Still, there is evidence, albeit sometimes weak and subject to econometric debate, that there is predictability on future returns. In accommodating these empirical facts, the theoretical asset pricing literature has basically taken two approaches: Augmenting the preferences of a single, representative agent, or complementing the endowment process by an additional exogenous process such as labor income. We offer a third alternative, and argue that several empirical facts can be generated within a model where standard heterogenous agents interact locally, thereby creating social dynamics. Our simulated economy provides evidence that a high propensity of agents to be influenced by their neighborhood results in valuation ratios that display a high degree of persistence, and which shows that dividends and prices need not be cointegrated. However, although social dynamics introduce high persistence, we find that econometric tests may still find evidence for predictability. It remains a challenging task for future research to empirically calibrate to what extent investment decisions are actually influenced by social dynamics. 


\section{References}

Alvarez, F. and Jermann, U. J. (2005). Using asset prices to measure the persistence of the marginal utility of wealth. Econometrica, 73(6):1977-2016.

Ang, A. and Liu, J. (2007). Risk, return, and dividends. Journal of Financial Economics, $85(1): 1-38$.

Baker, M. and Wurgler, J. (2007). Investor sentiment in the stock market. Journal of Economic Perspectives, 21(2):129-151.

Bansal, R. and Yaron, A. (2004). Risks for the long run: A potential resolution of asset pricing puzzles. Journal of Finance, 59(4):1481-1509.

Brown, J. R., Ivkovic, Z., Smith, P. A., and Weisbenner, S. (2008). Neighbors matter: Causal community effects and stock market participation. Journal of Finance, 63(3):1509-1531.

Campbell, J. Y. and Cochrane, J. H. (1999). By force of habit: A consumptionbased explanation of aggregate stock market behavior. Journal of Political Economy, 107(2):205-251.

Campbell, J. Y. and Shiller, R. J. (1987). Cointegration and tests of present value models. Journal of Political Economy, 95(5):1062-1088.

Campbell, J. Y. and Shiller, R. J. (1989). The dividend-price ratio and expectations of future dividends and discount factors. Review of Financial Studies, 1(3):195-228.

Cecchetti, S. G., Lam, P.-S., and Mark, N. C. (1990). Mean reversion in equilibrium asset prices. American Economic Review, 80(3):398-418.

Cecchetti, S. G., Lam, P.-S., and Mark, N. C. (2000). Asset pricing with distorted beliefs: Are equity returns too good to be true? American Economic Review, 90(4):787-805.

Chan, Y. L. and Kogan, L. (2002). Catching up with the joneses: Heterogeneous preferences and the dynamics of asset prices. Journal of Political Economy, 110(6):12551285.

Chen, A.-S. and Zhang, T.-W. (2007). Autocorrelation, structural breaks and the predictive ability of dividend yield. Applied Economics, 39:645-652.

Cochrane, J. H. (2001). Asset Pricing. Princeton University Press, Princeton. 
Cochrane, J. H. (2008). The dog that did not bark: A defense of return predictability. Review of Financial Studies, 21(4):1533-1575.

Collard, F., Fève, P., and Ghattassi, I. (2006). Predictability and habit persistence. Journal of Economic Dynamics and Control, 30:2217-2260.

Constantinides, G. M. and Duffie, D. (1996). Asset pricing with heterogeneous consumers. Journal of Political Economy, 104(2):219-240.

Esteve, V. and Prats, M. A. (2010). Threshold cointegration and nonlinear adjustment between stock prices and dividends. Applied Economics Letters, 17:405-410.

Fama, E. F. and French, K. R. (1988). Dividend yields and expected stock returns. Journal of Financial Economics, 22:3-27.

Favero, C. A., Gozluklu, A. E., and Tamoni, A. (2010). Demographic trends, the dividend-price ratio and the predictability of long-run stock market returns. Journal of Financial And Quantitative Analysis, forthcoming.

Goyal, A. and Welch, I. (2003). Predicting the equity premium with dividend ratios. Management Science, 49(5):639-654.

Grinblatt, M., Keloharju, M., and Ikäheimo, S. (2008). Social influence and consumption: Evidence from the automobile purchases of neighbors. Review of Economics and Statistics, 90(4):735-753.

Hamilton, J. D. (1989). A new approach to the economic analysis of nonstationary time series and the business cycle. Econometrica, 57(2):357-384.

Han, H.-L. (1996). Cointegration and tests of a present value model in the stock market. Applied Economics, 28(2):267-272.

Haug, A. A. and Basher, S. A. (2011). Linear or nonlinear cointegration in the purchasing power parity relationship? Applied Economics, 43(2):185-196.

Hong, H., Kubik, J. D., and Stein, J. C. (2004). Social interaction and stock-market participation. Journal of Finance, 59(1):137-163.

Hule, R. and Lawrenz, J. (2010). Return predictability and social dynamics. Working paper, (SSRN).

Jackson, M. O. (2008). Social and Economic Networks. Princeton University Press, Princeton. 
Kaustia, M. and Knüpfer, S. (2010). Peer performance and stock market entry. Working paper, (London Business School).

Koijen, R. S. and Van Nieuwerburgh, S. (2009). Financial economics, return predictability and market efficiency. In Meyers, R. A., editor, Encyclopedia of Complexity and Systems Science. Springer.

Lettau, M. and Ludvigson, S. (2001). Consumption, aggregate wealth, and expected stock returns. Journal of Finance, 56(3):815-849.

Lettau, M. and Ludvigson, S. (2010). Measuring and modeling variation in the riskreturn trade-off. In Ait-Sahalia, Y. and Hansen, L. P., editors, Handbook of Financial Econometrics, volume 1 of Handbooks of Finance. Elsevier, Amsterdam.

Lettau, M. and Van Nieuwerburgh, S. (2008). Reconciling the return predictability evidence. Review of Financial Studies, 21(4):1607-1652.

Lewellen, J. (2004). Predicting returns with financial ratios. Journal of Financial Economics, 74:209-235.

Lucas, R. E. J. (1978). Asset prices in an exchange economy. Econometrica, 46(6):14291445 .

Masih, A. M. M. and Masih, R. (2004). Fractional cointegration, low frequency dynamics and long-run purchasing power parity: An analysis of the australian dollar over its recent float. Applied Economics, 36:593-605.

Masih, R., Masih, A. M. M., and Mic, K. (2010). Model uncertainty and asset return predictability: An application of bayesian model averaging. Applied Economics, 42(15):1963-1972.

Mehra, R. and Prescott, E. C. (2003). The equity premium in retrospect. In Constantinides, G. M., Harris, M., and Stulz, R. M., editors, Handbook of the Economics of Finance: Financial Markets and Asset Pricing, volume 1B of Handbooks in Economics. North-Holland, Amsterdam.

Rozeff, M. S. (1984). Dividend yields are equity risk premia. Journal of Portfolio Management, 11(1):68-75.

Shiller, R. J. (1984). Stock prices and social dynamics. Brookings Papers on Economic Activity, 2:457-498. 
Taylor, M. P. (1988). An empirical examination of long-run purchasing power parity using cointegration techniques. Applied Economics, 20(10):1369-1381.

Timmermann, A. (1995). Cointegration tests of present value models with a timevarying discount factor. Journal of Applied Econometrics, 10:17-31. 